\title{
XXXIV. Failure of Lagrange's Method of integrating Linear with Constant Coefficients
}

\author{
John Herapath Esq.
}

To cite this article: John Herapath Esq. (1828) XXXIV. Failure of Lagrange's Method of integrating Linear with Constant Coefficients, Philosophical Magazine Series 2, 3:15, 210-212, DOI: $10.1080 / 14786442808674611$

To link to this article: http://dx.doi.org/10.1080/14786442808674611

曲 Published online: 10 Jul 2009.

Submit your article to this journal $[\pi$

Џll Article views: 4

Q View related articles $\square$ 
errors, which must be applied to the observed pendulums to make them equal to the calculated lengths:

errors.

errors.

Paramatta . + .00212
Rio Janeiro + $\cdot 00266$
Bahia .... + $\cdot 00161$
Maranham .+ $\cdot 00399$
Rawak ... + $\cdot 00094$
Trinidad ..+ + 00376

Madras .....+ 00269

San Blas .. + +00418

Figeac .... + 00224

Bourdeaux $+\cdot 00323$

Clermont .. $+\cdot 00148$

Paris ...... 00103

About $50^{\circ}$ of latitude all the formulas very nearly agree with one another, and with observation. In receding more from the equator, the pendulums are shorter in the formula we are considering, than in the others; but the effect of this is not very perceptible except at the highest latitudes. At Port Bowen and Spitzbergen, the errors are - $\cdot 00239$ and - -00302 .

It appears then that, by lengthening the equatorial pendulum, we approach a little nearer to the anomalous experiments, and recede from all the rest within $50^{\circ}$ of the equator. The foregoing investigation proves that all the 40 observed pendulums can never be represented, without great discrepancies, by any one ellipticity. In my last formula all the pendulums, except the five anomalous ones, are placed on one and the same surface within the limits of the errors of observation. But no one pendulum within $50^{\circ}$ of the equator answers to its proper place in the surface of which the ellipticity is $\frac{1}{289}$. This surface is merely an imaginary mean, the offspring of calculation. It can have nothing to do with what is called local attraction: for it makes an excess of gravity at five particular stations, and, as far as experience enables us to pronounce, a defect of gravity every where else within the limits mentioned.

Feb. 14.

J. Ivory.

XXXIV. Failure of Lagrange's Method of integrating Linear with Constant Coefficients*. By John Herapath, Esq.†

$\mathrm{F}$ we suppose the roots $r, r_{1}, r_{2}$ of the equation

$$
r^{3}+\mathrm{A} r^{3}+\mathrm{Br}+\mathrm{C}=0
$$

- It should have been mentioned in my last paper, that the constants in (18) are not precisely the same as in (17), except the first two. In the other ternis several factors in the denominators were suppressed and understood in the constants, for brevity and ease of printing.

t Communicated by the Author. 
to be all equal, the three equations of condition, p. 23, which are asserted, p. 96, to give the "complete integral" of

$$
\frac{d^{3} y}{d} x^{3}+\mathrm{A} \frac{d^{2} y}{d x^{2}}+\mathrm{B} \frac{d y}{d x}+\mathrm{C} y=\mathrm{X}
$$

by Lagrange's method will become

$$
\begin{aligned}
r^{8} e^{r x}\left\{d p+d p_{1}+d p_{2}\right\} & =\mathrm{X} \\
d p+d p_{1}+d p_{3} & =0 \\
d p+d p_{1}+d p_{2} & =0
\end{aligned}
$$

giving obviously $\mathrm{X}=0$. That is, the equations of condition, which are said to furnish the "complete integral " of (a), and which therefore ought to give all cases of the integral without limiting the value of $\mathrm{X}$, fix in the above instance the value of this indefinite function to zero.

Any candid mind would not need a more decided proof of absurdity in the principles of Lagrange's method than the above; but as some may think it dealing a little too summarily with a process which has obtained so much celebrity, and may prefer an instance of failure in result to a theoretical exposition of absurdity in principle, I submit the following, taken not from any investigation of mine, but copied from a professed advocate of Lagrange in the last Number of this volume. We are informed, p. 96, that the "complete integral" of (a) is

$$
\begin{aligned}
& \text { " } y=\frac{e^{r x}\left\{c+\int \mathrm{X}_{e}-r x d x\right\}}{r-r_{1} \cdot r-r_{2}} \\
& +\frac{e^{r_{1} x}\left\{c_{1}+\int \mathrm{X}_{e}-r_{1} x d x\right\}}{r-r_{1} \cdot r_{1}-r_{2}} \\
& +\frac{e^{r_{2} x}\left\{c_{2}+\int \mathrm{x}_{\left.e^{-r_{2} x} d x\right\}}\right.}{r-r_{2} \cdot r_{1}-r_{2}} \cdot \cdots
\end{aligned}
$$

Now this being the "complete integral," must give the value of $y$ whatever values be assigned to $r, r_{1}, r_{2}$ and $\mathrm{X}$. Putting for simplicity $\mathrm{X}=0$, and then supposing $r=r_{1}$ the above equation becomes

$$
y=e^{r x} \frac{c-c_{1}}{0 \times\left(r-r_{2}\right)}+\frac{c^{2} e^{r_{2} x}}{\left(r-r_{2}\right)^{2}}
$$

that is, the value of $y$ is infinite unless the arbitrary constants $c, c_{1}$ are equal, or certain functions of $r, r_{\mathbf{1}^{*}}$ But $c, c_{1}$ being in the strict sense of the word "arbitrary constants," are not necessarily functions of $x$ or $r, r_{1}$; and therefore the infinite value of $y$ remains. We however know from other principles that $y$ may be finite. 
212 Mr. Herapath on the Failure of Lagrange's Method, \&\&.

Lest it be supposed that the failure of Lagrange's method may be remedied by putting the pretended "complete integral " under the form of our (17), so as to take away the zero divisors, and thus bring out the complete solution: I shall now examine this point. For the sake of simplicity I will take an equation of the second order only, the lowest to which Lagrange's method can be fairly applied; and which from its having but two roots, and therefore but one difference between them, is peculiarly adapted to exhibit perspicuously the justice or injustice of our observations.

If $r, r_{1}$ be the roots of the equivalent algebraic equation, the " complete integral" is

$$
y=\frac{c e^{r x}-c_{1} e^{r_{1} x}+e^{r x} \int \mathbf{X}_{e}-r x d x-e^{r, x} \int \mathbf{X}_{e}-r_{1}^{2} d x}{r-r_{t}} .
$$

And if we put $\mathrm{X}=0$

$$
y=\frac{c e^{r x}-c_{1} e^{r_{1} x}}{r=r_{1}}=c e^{r_{1} x} \int e^{\left(r-r_{1}\right) x} d x+c_{1} e^{r x} \int e^{\left(r_{1}-r\right) x} d x
$$

must be the "complete integral" of

$$
\frac{d^{2} y}{d x^{2}}+\mathrm{A} \frac{d y}{d x}+\mathrm{B} y=0 .
$$

But when $r=r_{1}$ the latter expression for the "complete integral" is

$$
y=\left(c+c_{1}\right) x e^{r x}
$$

which is evidently not the "complete integral," were it only that $c+c_{1}$ makes but one arbitrary constant. The integral by our formula (17) is

$$
y=\left\{c_{\mathrm{s}}+c x\right\} e^{r x}
$$

in which two aritrary constants appear.

\section{J. Herapaju.}

P.S. Since writing the above, I have examined with more attention Lagrange's method, and I find that the solution (b), which is professed to be taken from Lacroix's great work, as the " complete integral" by Lagrange's method, is not strictly the integral which this method gives. The result of Lagrange's contains less of absurdity than the above, but nevertheless fails to give the complete solution. I have not found where Lagrange published his method, nor what exanjples of it he gave. If that of Lacroix be one, it is a curious circumstance that he should fail both in method and deduction. 